\title{
Single center experience from Egypt about fulminant hepatic failure in children
}

\begin{abstract}
Aim: To assess fulminant hepatic failure (FHF) in children and its interrelating factors.

Methods and materials: A retrospective review study of 24 patients less than 17 years old who presented to the National Liver Institute with FHF over a period of two years was done. FHF was defined as the presence of acute liver failure with or without encephalopathy without pre-existing liver disease, within 8 weeks of the onset of clinical liver disease. Hepatitis A virus (HAV) IgM antibodies, Hepatitis B virus surface antigen (HBsAg), IgManti Hepatitis B core antigen (HBc), Hepatitis E virus (HEV) IgM and Hepatitis C virus (HCV) RNA in nested PCR were done in all patients. Special investigations like alpha fetoprotein, serum copper, blood culture, drug levels and other metabolic studies were carried out whenever indicated. Detailed clinical evaluations and routine hepatic laboratory profile were done. Results: Acute hepatitis-A virus was the commonest cause. Severe coma was significantly present among non-survivals and no ascites. Patients who survived had got significantly lower level of prothrombin time, they also had significantly lower rate of descent of prothrombin time.
\end{abstract}

Conclusion: Hepatitis A virus was the commonest etiology of FHF. The peak level of total serum bilirubin, the rate of change of the prothrombin time/day and ammonia level were significant predictors of mortality.

Keywords: fulminant hepatic failure, FHF, HAV, children, national lver institute, Egypt
Volume 10 Issue 4 - 2020

\author{
Elsayed I Ali Salama,' 'Nermin M Adawy,' \\ Ashraf Mansour ${ }^{2}$ \\ 'Department of Pediatrics, Menoufiya University, Egypt \\ ${ }^{2}$ Weill Cornell university, Qatar
}

Correspondence: Elsayed I Ali Salama, Department of Pediatrics, National Liver Institute, Menoufiya University, Egypt, Tel 00974 30093779, Email elsayedsalama@yahoo.com

Received: July 14, 2020 | Published: July 3I, 2020

\section{Introduction}

Fulminant hepatic failure (FHF) is a medical emergency that can lead to serious damage and multi-organ failure. It should be distinguished from hepatic dysfunction where liver may still perform all the functions required to sustain life. ${ }^{1}$ While FHF is a relatively rare and devastating event in pediatric patients, it is frequently fatal in absence of liver replacement. Until the advent of liver transplantation, the mortality ranged from $50-90 \%{ }^{2}$ FHF is defined as an acute severe liver impairment with or without encephalopathy where there is no recognized underling liver disease. ${ }^{3}$ The traditional definition of FHF as a clinical syndrome characterized by coagulopathy and encephalopathy could be applied in adult patients. In children, encephalopathy is a late event that can be very difficult to diagnose in younger age group and is absent in 50\% of cases. ${ }^{3}$ FHF is caused by massive destruction of hepatocytes following a major insult usually viral, toxic or immune mediated attack. However, the exact process leading to profound hepatic damage is unknown. It seems to be multifactorial and depends on age susceptibility of the host and the extent of hepatic injury. ${ }^{4}$ Metabolic disorders (e.g., tyrosinemia, hereditary fructose intolerance, bile acid disorders, fatty acid oxidation defect and Wilson's disease), Budd Chiari and metastatic disease have been implicated in FHF. ${ }^{5}$ Viral hepatitis is the commonest cause of FHF in children of all age groups and accounting for $80 \%$ of cases, in the developing world, hepatitis A virus (HAV) infection is the most important etiological agent causing FHF in children whereas HBV is predominant in the Far East and hepatitis $\mathrm{C}$ virus (HCV) infection in Japan, in other side, in developed countries the chief offenders are drugs and toxins especially acetaminophen5. The aim of this study is to assess the clinical, laboratory characteristics, etiology and outcome of children with FHF, also evaluating the predictive factors affecting the outcome of FHF.

\section{Methods and materials}

Basic information such as age, gender, underlying diseases, clinical presentations, and complications was collected from clinical charts and nursing records of each patient. Laboratory tests were conducted at admission and after treatment. Our retrospective study included 24 patients, all are younger than 17 years who presented to the National Liver Institute, Egypt with FHF over a period of two years from 20032005. Diagnosis of FHF was established when an acute severe liver impairment with or without encephalopathy, and there is no recognized underling liver disease. ${ }^{3}$ Upon presentation and every 6 hours: blood glucose, arterial blood gases, electrolyte levels, prothrombin time and hematocrit were assessed. Upon presentation and daily: serum bilirubin (total and conjugated), Aspartate aminotransferase (AST), Alanine aminotransferase (ALT), serum albumin, creatinine and complete blood count, urine analysis, ammonia, total serum proteins were assessed. All serum samples were tested for: anti-HAV IgM, hepatitis B surface antigen (HBsAg), IgM antibodies to hepatitis B core antigen (IgM-anti $\mathrm{HBc}$ ) and IgM antibodies to hepatitis $\mathrm{E}$ virus (IgM anti HEV). All samples were screened for HCV RNA in nested PCR. Special investigations like alpha fetoprotein, copper studies (serum ceruloplasmin, urinary copper), blood culture, drug levels, serum and urine amino acids were carried out whenever indicated. All patients were nursed in the pediatric intensive care unit (PICU) with close monitoring and standard FHF protocols were applied. Antibiotics, fresh frozen plasma (FFP), anti-cerebral edema measures, were used whenever indicated. Upon presentation and every 6 hours, detailed clinical evaluations including history, physical signs of liver cell failure and staging of encephalopathy were done. The following definitions were used for staging of hepatic encephalopathy: Grade 1: Alert, depression of responsiveness, decreased appetite and mood changes. Grade 11: Lethargic, confused, drowsiness, hyperreflexia 
and asterixis. Grade 11l: Marked confusion, disorientation, irritability, agitation or reactivity only to noxious physical stimuli. Grade IV: Deep coma without reaction to vocal stimuli, response only to noxious physical stimuli. Time to hepatic encephalopathy was defined as time from first symptom to onset of encephalopathy. ${ }^{6}$

\section{Statistical analysis}

Clinical data were collected from one tertiary hospital in Egypt. A retrospective investigation was conducted to analyze the clinical characteristics of survival and non survival cases of FHF. The SPSS Statistics 23.0 software (SPSS Inc., Chicago, IL, USA) was used to perform statistical analysis of the data. Continuous variables were presented as median (interquartile range) (distribution of normality was checked by Kolmogorov-Smirnov test) and analyzed using the Mann-Whitney U test. Categorical variables were presented as counts and percentages, and analyzed by $\chi 2$ test or Fisher exact test as appropriate. A value of $\mathrm{P}<0.05$ was considered to be statistically significant. Based on the Mann-Whitney Z statistics' magnitudes, this algorithm can identify time windows containing significant incidences of low or high data rankings, where the window length is determined by the sample size. By repeating this process with sampling windows of varying duration ranking regimes of arbitrary onset and duration can be objectively identified in a time series. The simplicity of the procedure's output - a time series' most significant non-overlapping ranking sequences - makes it possible to graphically identify common temporal breakpoints and patterns of variability in the analyses of multiple time series.

\section{Results}

In our study, we found the age group of the patients presented with FHF was $51.518 \pm 63.477$ months. We found that, males were affected more than female, at the same time, female patients with FHF seemed to survive more.

Viral hepatitis was the commonest etiology among all patients with FHF (survivals and non-survivals). The etiology of FHF in 14 out of 24 of the children was viral hepatitis; HAV was the cause in $50 \%$ of them $(8 / 14)$. We found 4 patients $(12.5 \%)$ had autoimmune hepatitis, one patient who got HCV hepatitis at the same time, had survived. Two patients did not survive; one of them had HBV infection. One of the patients with HAV infection was diagnosed as Wilson disease for the first time to be diagnosed. We could not detect significant difference between survivals and non-survivals regarding the presence of fever and ammonia level was significantly different. Encephalopathy was found to be more presented and more severe among the non-survivals in our study, time to hepatic encephalopathy was significantly longer among non-survivals, and the time to reach encephalopathy was $19.1 \pm 11.32$ days vs. 1.8 days of survival. Fulminant hepatic failure was due to viral hepatitis (HAV and HBV) in 4 out of 6 survived patients, while in one third of the non-survivals, the cause of FHF was obscure. Three out of the eight patients with HAV infection had survived while the other five died. One patient got co-infection with HAV and CMV and this patient died. HSV was found in two of our patients, one of them died and the other one survived. However, the combination of HAV infection and Wilson disease in our patient may explain the aggressive course of Wilson disease in our patient after having HAV infection. Mortality rate was found to be $75 \%$ among our patients, patients died had higher peak total bilirubin level than survivals. Also, the rate of serum bilirubin ascend was significantly higher among non-survivals. Peak level of total serum bilirubin and the rate of descent of the prothrombin time/day, ammonia level and degree of encephalopathy were found to be the significant predictors of mortality of fulminant hepatic failure in our patients (Tables 1-4).

Table I Comparison of demographic and clinical data of patients presented with fulminant hepatic failure (non-survivals and survivals)

\begin{tabular}{|c|c|c|c|c|c|}
\hline \multicolumn{2}{|c|}{ Demographic and clinical data } & \multirow{2}{*}{$\begin{array}{l}\text { Non-survivals } \\
10(55.6 \%) \\
8(44.4 \%)\end{array}$} & \multirow{2}{*}{$\begin{array}{l}\text { Survivals } \\
2(33.3 \%) \\
4(66.7 \%)\end{array}$} & \multirow{2}{*}{$\begin{array}{l}\text { Test of sig. } \\
\text { Fisher's Exact }\end{array}$} & \multirow{2}{*}{$\begin{array}{c}\mathbf{P} \\
0.640\end{array}$} \\
\hline Age (yrs): & $\begin{array}{l}<2 Y R \\
>2 Y R\end{array}$ & & & & \\
\hline Sex: & $\begin{array}{l}\text { Males } \\
\text { Females }\end{array}$ & $\begin{array}{ll}13 & (72.2 \%) \\
5 & (27.8 \%)\end{array}$ & $\begin{array}{l}2(33.3 \%) \\
4(66.7 \%)\end{array}$ & Fisher's Exact & 0.150 \\
\hline Fever: & $\begin{array}{l}\text { Yes } \\
\text { No }\end{array}$ & $\begin{array}{l}8(44.4 \%) \\
10(55.6 \%)\end{array}$ & $\begin{array}{l}2(33.3 \%) \\
4(66.7 \%)\end{array}$ & Fisher's Exact & 1.000 \\
\hline Hepatomegaly: & $\begin{array}{l}\text { Yes } \\
\text { No }\end{array}$ & $\begin{array}{l}7(38.9 \%) \\
\text { II (61.1\%) }\end{array}$ & $\begin{array}{l}2(26.7 \%) \\
4(66.7 \%)\end{array}$ & Fisher's Exact & 1.000 \\
\hline Ascites: & $\begin{array}{l}\text { Yes } \\
\text { No }\end{array}$ & $\begin{array}{l}8(44.4 \%) \\
10(55.6 \%)\end{array}$ & $\begin{array}{l}0(0 \%) \\
6(100 \%)\end{array}$ & Fisher's Exact & 0.066 \\
\hline Bleeding: & $\begin{array}{l}\text { Yes } \\
\text { No }\end{array}$ & $\begin{array}{l}6(33.3 \%) \\
12(66.7 \%)\end{array}$ & $\begin{array}{l}2(33.3 \%) \\
4(66.6 \%)\end{array}$ & Fisher's Exact & 1.000 \\
\hline Encephalopathy: & $\begin{array}{l}\text { No } \\
\text { Yes }\end{array}$ & $\begin{array}{l}0(0 \%) \\
18(100 \%)\end{array}$ & $\begin{array}{l}3(50 \%) \\
3(50 \%)\end{array}$ & Fisher's Exact & $0.01 *$ \\
\hline $\begin{array}{r}\text { Grades of coma: } \\
\text { Grade } \\
\text { Grade } \\
\text { Grade }\end{array}$ & $\begin{array}{l}1-11 \\
111 \\
2\end{array}$ & $\begin{array}{l}0(0 \%) \\
12(66.7 \%) \\
6(33.3 \%)\end{array}$ & $\begin{array}{l}\text { I (I6.7\%) } \\
\text { I (16.7\%) } \\
\text { I (16.7\%) }\end{array}$ & Fisher's Exact & $0.002 *$ \\
\hline
\end{tabular}




\begin{tabular}{|c|c|c|c|c|}
\hline Demographic and clinical data & Non-survivals & Survivals & Test of sig. & $\mathbf{P}$ \\
\hline \multicolumn{5}{|l|}{ Aetiolgies } \\
\hline \multicolumn{5}{|l|}{ Viral: } \\
\hline HAV & $5(27.8 \%)$ & $3(50 \%)$ & & \\
\hline HBV & $2(11.1 \%)$ & I (I6.7\%) & & \\
\hline $\mathrm{HCV}$ & $0(0 \%)$ & $\mathrm{I}(\mathrm{I} 6.7 \%)$ & & \\
\hline HSV & I (5.6\%) & $\mathrm{I}(16.7 \%)$ & $\times 2$ & $\mathrm{P}$ \\
\hline $\mathrm{HAV}+\mathrm{CMV}$ & I (5.6\%) & $0(0 \%)$ & 4.801 & 0.308 \\
\hline Autoimmune: & $3(16.7 \%)$ & $0(0 \%)$ & & \\
\hline Unknown: & $6(33.33 \%)$ & $0(0 \%)$ & & \\
\hline
\end{tabular}

Table 2 Comparison of blood chemistry among non-survivals and survivals in patients with fulminant hepatic failure

\begin{tabular}{|c|c|c|c|c|}
\hline Blood count and chemistry & Non-survivals & Survivals & Test of sig. & $\mathbf{P}$ \\
\hline $\mathrm{pH}$ of the blood & $\begin{array}{l}7.315 \\
\pm 0.137\end{array}$ & $\begin{array}{l}7.366 \\
\pm 0.0565\end{array}$ & $\begin{array}{l}\text { Mann-Whitney } \\
\text { Z I.374 }\end{array}$ & 0.169 \\
\hline Serum Sodium (mmol/L) & $\begin{array}{l}131.778 \\
\pm 7.780\end{array}$ & $\begin{array}{l}136.00 \\
\pm 3.224\end{array}$ & $\begin{array}{l}\text { Mann-Whitney } \\
\text { Z I.303 }\end{array}$ & 0.193 \\
\hline Serum Potassium (mmol/L) & $\begin{array}{l}3.7667 \\
\pm 0.807\end{array}$ & $\begin{array}{l}3.900 \\
\pm 0.707\end{array}$ & $\begin{array}{l}\text { Mann-Whitney } \\
\text { Z 0.30I }\end{array}$ & 0.763 \\
\hline $\begin{array}{l}\text { AST (U/L): } \\
\text { On admission }\end{array}$ & $962.67 \pm 945.51$ & $923.50 \pm 586.87$ & Mann-Whitney Z 0200 & 0.841 \\
\hline On discharge & $647.22 \pm 1007.8$ & $579.33 \pm 505.7$ & Mann-Whitney Z 3.134 & 0.463 \\
\hline Rate of change/day & $10.976 \pm 407.23$ & $103.4 \pm 142.91$ & Mann-Whitney Z 0.467 & 0.641 \\
\hline ALT (U/L): & $52328+528.49$ & $10502+94260$ & Mann_Whitnev $7 \quad 767$ & 0841 \\
\hline On discharge & $326.72 \pm 310 . .68$ & $767.83 \pm 1097.4$ & Mann-Whitney Z 0.733 & 0.463 \\
\hline Rate of change/day & $13.52 \pm 135.29$ & $83.07 \pm 149.91$ & Mann-Whitney Z I.000 & 0.317 \\
\hline Serum creatinine (mg/dL) & $\begin{array}{l}0.7111 \\
\pm 0.8072\end{array}$ & $\begin{array}{l}0.2333 \\
\pm 0.8165\end{array}$ & $\begin{array}{l}\text { Mann-Whitney } \\
\text { Z I.465 }\end{array}$ & 0.143 \\
\hline WBCs $(1000 / L)$ & $\begin{array}{l}\text { II.8722 } \\
\pm 7.842\end{array}$ & $\begin{array}{l}9.400 \\
\pm 6.296\end{array}$ & $\begin{array}{l}\text { Mann-Whitney } \\
\text { Z } 0.800\end{array}$ & 0.424 \\
\hline $\mathrm{Hb}(\mathrm{gm} / \mathrm{L})$ & $\begin{array}{l}8.7444 \\
\pm 2.369\end{array}$ & $\begin{array}{l}10.100 \\
\pm 0.723\end{array}$ & $\begin{array}{l}\text { Mann-Whitney } \\
\text { Z I.937 }\end{array}$ & 0.053 \\
\hline
\end{tabular}

* Significant

Table 3 Predictors of mortality in patients presented with FHF

\begin{tabular}{|c|c|c|c|c|}
\hline Liver function tests & non-survivals & Survivals & Test of sig. & $\mathbf{P}$ \\
\hline \multicolumn{5}{|l|}{ T. Serum Bilirubin (mg/dL) } \\
\hline On admission & $22.194 \pm 14.870$ & $10.983 \pm 5.582$ & Mann-Whitney Z I.835 & $0.067 *$ \\
\hline On discharge & $28.683 \pm 12.084$ & $7.633 \pm 4.089$ & Mann-Whitney Z 3.068 & $0.002 *$ \\
\hline Peak level & $34.1667 \pm 13.5005$ & $20.333 \pm 18.770$ & Mann-Whitney Z 3.134 & $0.002 *$ \\
\hline Rate of change**/day & $2.262 \pm 5.197$ & $2.44 \pm 2.865$ & Mann-Whitney Z 2.40I & $0.016 *$ \\
\hline
\end{tabular}


Table continued...

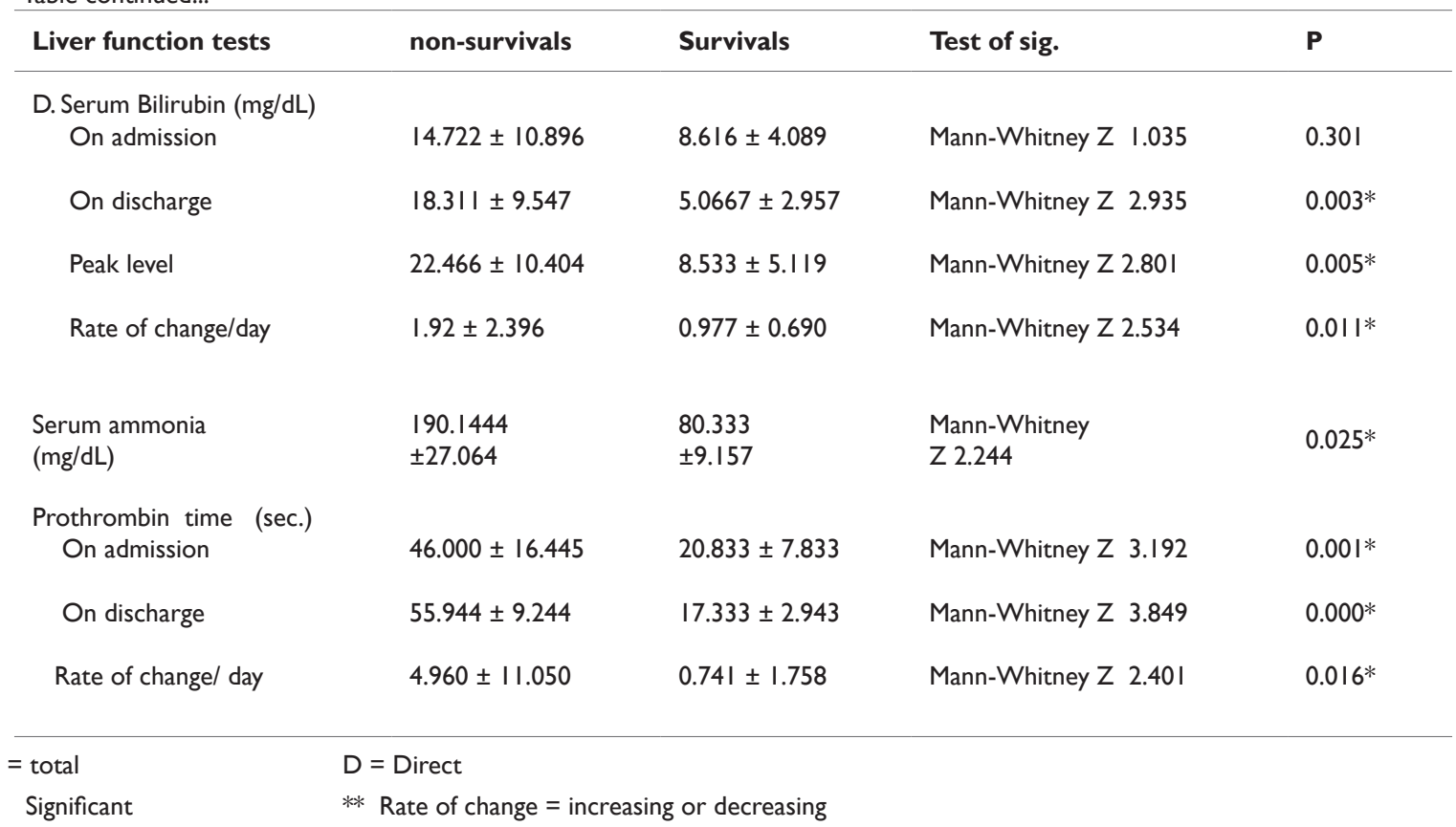

Table 4 Predictors of mortality in patients presented with FHF

\begin{tabular}{|c|c|c|c|c|c|c|}
\hline $\begin{array}{l}\text { Laboratory } \\
\text { predictors }\end{array}$ & B & SE & $\begin{array}{l}\text { Wald } \\
\text { Chi- square }\end{array}$ & Df & Sig. & $\operatorname{Exp}(B)$ \\
\hline \multicolumn{7}{|l|}{$\begin{array}{l}\text { Total. serum bilirubin }(\mathrm{mg} / \mathrm{dL}) \text { : } \\
\text { Step la: }\end{array}$} \\
\hline TSB. peak & 0.216 & 0.094 & 5.289 & I & 0.021 & $|.24|$ \\
\hline Constant & 3.356 & 1.736 & 3.735 & I & 0.053 & 0.035 \\
\hline \multicolumn{7}{|l|}{ Step $2 b:$} \\
\hline TSB. peak & 5.100 & 718.114 & 0.000 & 1 & 0.994 & 164.091 \\
\hline \multicolumn{7}{|l|}{ Prothromin Time (sec.): } \\
\hline Rate of descent. & 3.425 & 741.055 & 0.000 & I & 0.996 & 30.814 \\
\hline Constant & 102.239 & |47.59| & 0.000 & I & 0.994 & 0.000 \\
\hline
\end{tabular}

TSB, total serum bilirubin; B, true slope of linear regression; Exp B, explained B; Constant, the residual variability in linear regression assumptions; Rate of descent, daily decrease of prothrombin time in second; SE, standard error; Df, degree of freedom

\section{Discussion}

Fulminant hepatic failure, the sudden and severe shutdown of the liver functions, is particularly distressing as it occurs acutely in previously healthy children and progresses rapidly despite all modern treatment. ${ }^{5}$ The impact of liver transplantation on survival of patients who have acute liver failure has been dramatic. One-year survival may approach $70 \%$ to $80 \%$. In fact, liver transplantation is the proven therapy for FHF. ${ }^{7}$ At the same time, rapid deterioration in the child's clinical condition may decrease the chance of survival and normal neurological outcome even with liver transplantation. Spontaneous recovery of FHF remains unpredictable. This created a need for early prognostic indicators to select the patient most likely to benefit at a time when liver transplantation is still feasible. Various criteria have been used in adults to establish a prognosis, the most widely applied of which is the King's College hospital criteria, which were found to have reasonable, though not perfect, discriminatory value for this purpose. ${ }^{8}$ In children, a clear set of indication for liver transplantation have not been outlined. Many studies have tried to verify characters of survivals and non-survivals and evaluate the criteria of predictors of mortality among the pediatric patients.

In our study, the age group of the patients presented with fulminant hepatic failure was $51.518 \pm 63.477$ months. Li et al., ${ }^{9}$ found that the mean age group of FHF in children was $4.22 \pm 5.49$ years and Lee et al reported age group of 27 months. ${ }^{9,10}$ Atypical presentation of FHF in young children accounting for the occasional delay in diagnosis or even in missed diagnosis in this age group, may have a role in the outcome. Inspite of that, we found that, patients who survived seemed to be younger than non-survivals. ${ }^{11}$ This may be explained by the small sample size. Chen and Lee reported the same result. They found that older age group (more than 2 year) is significantly correlated with mortality. ${ }^{10,11}$ Inspite of the fact that, distribution of FHF is equal among males and females, we found that, males were affected more than female. At the same time, female patients with FHF seemed to survive more. However, this male/female ratio should be correlated to 
male/female distribution of the whole population. Li et al., ${ }^{9}$ reported the same result, where male to female patients with FHF in his study were $24: 1410$. Mortality rate was found to be $75 \%$ among our patients. Lee and Chen and Andogdu, reported the same mortality rate of $75 \%, 71 \%, 71 \%$ and $67.6 \%$ respectively., ${ }^{911,12}$ Meanwhile, Li, Lee and Bhatia reported lower mortality rate of $55.3 \%, 39 \%$ and $52 \%$ respectively.,13 On the other hand, another study done in Nigeria (2001), reported a higher mortality rate of $95.2 \% .^{14}$

The two major neurological complications of fulminant hepatic failure are hepatic encephalopathy and cerebral edema. They can present simultaneously in a fulminant manner. Cerebral edema is the leading cause of death in patients with FHF. It occurs in $75 \%$ of patients with stage IV hepatic encephalopathy. Both conditions can present with similar symptoms. ${ }^{15}$ This may explain why encephalopathy was found to be more presented and more severe among the non-survivals in our study. Time to hepatic encephalopathy was significantly longer among non-survivals. In agreement with our results, Chen and Aydogdu, Miyake and Chan found that hepatic encephalopathy grade III and IV was significantly correlated with mortality of children with FHF. ${ }^{12,13,16,17}$ It has been recognized that, the interval between the onset of icterus and encephalopathy conveyed important etiologic and prognostic information. Regardless of etiology, patients with hyperacute liver failure had a relatively favourable spontaneous survival rate of 35 percent. ${ }^{11}$ Lee reported that delay of hepatic encephalopathy (10.5 days vs 3.5 days) was correlated with mortality. In another study, patients who did not survive FHF had $18 \pm 16$ days to reach stage II encephalopathy while survivals had $5 \pm 5$ days. Ramseh found that, the time to reach the onset of coma was 5.8 days among survivals vs. 10.8 days among non-survivals, while $\mathrm{Li}$ et al found that the time taken by the survivals to reach encephalopathy was $1.5 \pm 0.71$ days vs. $11.75 \pm 8.2$ days. ${ }^{9} 10,12,18$ In our study, in agreement with the previous results, among non-survivals, the time to reach encephalopathy was $19.1 \pm 11.32$ days vs. 1.8 days of survival. This result could be explained by the etiology of fulminant hepatic failure. Four out of six patients who had survived, the etiology of FHF was hepatotrophic viral hepatitis (HAV and HBV) which usually known to pursued hyper-acute course while in one third of the non-survivals the cause of FHF was obscure. This unknown etiology dominated as the cause of sub-acute liver failure and is known to be associated with a dismal survival rate (approximately 14\%). ${ }^{11,19}$

In viral hepatitis, fever is present in the icteric phase. In endemic area, if fever is present in the icteric phase of hepatitis, Typhoid fever also should be considered in the differential diagnosis. These patients with presumptive diagnosis of Typhoid fever should be treated even before the results of blood cultures with excellent response to treatment. ${ }^{20,21}$ Lee and Sachin reported that presence of fever during FHF is significantly correlated with mortality. ${ }^{19,10}$ In our study, we could not detect significant difference between survivals and nonsurvivals regarding the presence of fever. Andogdu et al and Chen et al reported that patients who did not survive had higher peak total bilirubin level than survivals. ${ }^{12,13}$ Lee et al, described a level of 299 $\mathrm{mol} / \mathrm{L}$ vs. $80 \mathrm{~mol} / \mathrm{L} 10$. Sachin reported $10.6 \mathrm{mg} / \mathrm{dl}$ among survivals vs. $13.9 \mathrm{mg} / \mathrm{dl}$ among non-survivals 18 . Rivera reported much higher level among non-survivals, $30 \pm 19 \mathrm{mg} / \mathrm{dL}$ vs. $11 \pm 9 \mathrm{mg} / \mathrm{dL}$ among survivals 18. Li reported a level of $25.17 \pm 14.89 \mathrm{mg} / \mathrm{dL}$ vs. $9.89 \pm 7.41$ $\mathrm{mg} / \mathrm{dL} .{ }^{9}$ These results go with our results. Also, the rate of serum bilirubin ascend was significantly higher among non-survivals.

In fulminant hepatic failure, all clotting factors synthesized by the liver exhibit depressed plasma activity. Factor II, with a half-life of 2 hours, is the first to be depleted with hepatocellular dysfunction and the first to be replaced with recovery. Coagulopathy is often complicated by DIC and thrombocytopenia that can be explained by inadequate thrombopioetin mRNA transcripton in the liver. Coagulopathy could be silent or present as a spontaneous and fatal intra cranial bleeding..$^{22,23}$ In our results, survivals had significantly lower prothrombin time (on admission and discharge) than nonsurvivals and lower rate of prothrombin descent than them. However, there was no significant difference as regard bleeding between the two groups. This could be explained by the presence of other factors that may had a role in bleeding (e.g., thrombocytopenia) rather than coagulopathy. In agreement with that of, Lee et al. Chan et al, and Sachin et al, reported higher prothrombin time among non-survivals, However, Rivera et al; (1997); reported a different result, the nonsurvivals got $2.25 \pm 6 \mathrm{~second} /$ day rate of prothrombin descend vs 13.4 second/day of survivals. ${ }^{10,17-19}$

Inspite of the fact that acute liver failure is an uncommon complication of acute viral hepatitis, viral hepatitis remains a major cause of FHF worldwide18. In our study, viral hepatitis was the commonest etiology among all patients with FHF (survivals and nonsurvivals). In the developed countries, HBV is the most important cause in endemic areas while in the developing world, hepatitis A is the most important etiological agent causing FHF in children. ${ }^{17}$ The incidence of FHF in HAV is very low being $<0.01 \%$. Despite the relatively mild infection that is observed with $\mathrm{HAV}$, it accounts for a substantial proportion (10-20\%) of pediatric liver transplantation. The survival rate is greater than $50-60 \%$ but if encephalopathy occurs, it will result in poor outcome. Factors responsible for the development of liver failure in these patients are unclear. The size of the inoculums, genetic background of the host, and co-infection may be of importance. ${ }^{24}$ In our study the etiology of FHF in fourteen out of twenty-four of the children was viral hepatitis. More than $50 \%$ of them (8/14), the etiology was HAV. Three out of the eight patients with HAV infection had survived while the other five died. Aydogdu detected acute viral hepatitis in $35.2 \%$ of his FHF patients where HAV represented 26.4\%. ${ }^{12}$ Another study done in Pakistan (2000), reported that HAV is a significant cause of liver failure among infant and children admitted to the hospital for advanced acute onset liver disease (40\%). ${ }^{24}$ These results highlight that fulminant hepatic failure is largely a preventable disease and large percent of cases can be prevented by immunization and hygienic measures.

One of the patients with HAV infection was diagnosed as Wilson disease for the first time. Diagnosis of Wilson disease may be missed due to the heterogeneity of clinical presentation 11 . A minority of patients with Wilson disease presented as fulminant hepatic failure. Children with fulminant Wilson disease characterized by rapidly progressive jaundice, coagulopathy and encephalopathy and the presence of Kayser Fleisher rings. The associated intra-vascular comb's negative hemolytic anemia, relatively low serum aminotransferases, low or even undetectable serum alkaline phosphatase levels may help in the diagnosis of Wilson disease. ${ }^{25}$ Chen described two cases of Wilson disease with fulminant hepatic failure as the first manifestation 12 . In (2003), a study done on Turkish children with fulminant hepatic failure and reported that $12.5 \%$ of the patients were diagnosed as Wilson disease. ${ }^{13}$ Chan reported that Wilson disease was found in 3/31 of children with FHF 17, However, the combination of HAV infection and Wilson disease in our patient may raise the question whether HAV affect or aggravate the presentation of Wilson disease! Suhhaveva reported that, hepatotropic viruses in some patients with hepato-cerebral dystrophy deteriorate hepatic lesion caused by copper imbalance. ${ }^{26}$ Copper level was found to be significantly higher in patients with viral hepatitis than in the control group. This is probably 
resulted from defense strategies of the organism and induced by the hormone-like substances. ${ }^{27}$ This may explain the aggressive course of Wilson disease in our patient after having HAV infection.

Fulminant hepatic failure can be associated with infection with multiple viruses. Kumar reported that, seven patients (26\%) with FHF got multiple virus co-infection. Five out of seven of these patients had $\mathrm{HAV}$ and $\mathrm{HEV}$, one patient got HBV and HAV and another patient got HEV and HBV. ${ }^{28}$ In our study, one patient got co-infection with HAV and CMV and this patient died. HSV was found in two of our patients, one of them died and the other one survived. Ichai described two cases got HSV2 super infection of an anti-HSV 1 positive patient and two HSV super infection of an HBV-related chronic liver disease. HSV super-infection had significantly contributed to liver dysfunction aggravation and death. ${ }^{29}$ Chan described $1 / 31$ of his patients with FHF got HSV infection 18. Diagnosis of HSV hepatitis is difficult to be established, in the absence of specific clinical signs which may suggest the need for early administration of acyclovir in patients with suspected HSV hepatitis without waiting for virologic confirmation. ${ }^{29}$ Autoimmune hepatitis has been reported as a common cause of liver failure in patients referred for liver transplantation. ${ }^{30}$ Acute presentation of autoimmune hepatitis is thought to be uncommon, however, U S National Institutes of Health Acute Liver Failure, studied autoimmune hepatitis accounted for $7 \%$ of patients registered. ${ }^{5}$ Patients with acute presentation differed significantly with regard albumin and bilirubin level. They also have less fibrosis and greater interface hepatitis. Zone 3 necrosis in their liver biopsy seemed to be specific. ${ }^{31}$ Cuarterolo described that, $33 \%$ of autoimmune hepatitis children had initial presentation as FHF their course was aggressive not responding to immunosuppressive with unfavorable evolution. ${ }^{32}$ In our study, four $(12.5 \%)$ patients had autoimmune hepatitis. One patient had survived who got HCV hepatitis at the same time. Two patients did not survive; one of them had HBV infection. It is well known that a wide range of viruses have been associated with the onset of auto-immune hepatitis. The most commonly associated is HCV. The molecular structure of $\mathrm{HCV}$ polyprotein in part resembles that of a component of cytochrome P450, a phenomenon termed molecular mimicry. This may explain the presence of $\mathrm{HCV}$ among these patients. ${ }^{5}$ In a good percent of cases, the etiology of FHF is indeterminate, these children are unlikely to recover without transplantation. HBV mutant, hepatitis non-A, non-B, non- $\mathrm{C}$ or other medications and toxins that are not tested for because they are thought to be insignificant may explain this group of patients4. Twenty five percent of our patients got unidentifiable etiology for fulminant hepatic failure. None of these patients had survived. Chan et al 2004, reported cryptogenic etiology in 14/31. Aydogdu et al; found undetectable cause in $44.1 \%$ of his patients. Many studies tried to predict the mortality of fulminant hepatic failure. ${ }^{9-11,17,18,33-35}$ Dhawan described that: age $>2.5$ years, INR, bilirubin and WBCs are the factors associated with early death36. Lee et al; (2005), described that: Time to onset of encephalopathy $>7$ days, prothrombin time $>55 \mathrm{secs}, \mathrm{AST}<2384 \mathrm{U} / \mathrm{L}$ are independent predictors for liver failure. In another study, peak ammonia $>200$ micro M/L was the only independent factor significantly associated with mortality. ${ }^{10,17,33}$ In our study, peak level of total serum bilirubin and the rate of descent of the prothrombin time /day were found to be the only significant predictors of mortality of fulminant hepatic failure in our patients. ${ }^{34}$

\section{Conclusion}

Mortality of fulminant hepatic failure is high, and the commonest etiology is viral infections, particularly HAV. The peak level of total serum bilirubin, the rate of change of the prothrombin time/daily and ammonia level were significant predictors of mortality. We are still in need for big group of patients from multicenter in Egypt to elucidate thas results.

\section{Acknowledgments}

For my colleges in National Liver Institute, Egypt.

\section{Conflicts of interest}

The authors do not declare any conflict of interest in relation to this article.

\section{Funding}

None.

\section{References}

1. Whittington PF. Fulminant hepatic failure in children. In: FJ Suchy, editor Liver diseases in children. Mosby: St Louis; 1994. p. 180-213.

2. Miyak Y, Sakaguchi K, Ikeda H, et al. New prognostic scoring model for liver transplantation in patients with non-acetaminophen-related Fulminant hepatic failure. Transplantation 2005;80(7):930-936.

3. Hoofnagle J, Carithers R, Shaio C, et al. Fulminant hepatic failure: Summary of a workshop. Hepatology. 1995;21(1):240-252.

4. John B, Nada Y, Robert H. Acute liver failure in children. Clin Liver Dis 2006;10(1):149-68.

5. Dam Sheila Sherlock: Diseases of the liver and biliary system in children. DA Kelly editor. 350 Main St Massachusetts USA 2004. p. 127-161.

6. Singer M, Suter PM. Acute hepatic failure. In: Webb AR, Shapiro M J, editors. Oxford Textbook of Critical Care. Oxford: Oxford University Press; 1999.

7. McCulloch D, Goddard A, Miller J, et al. Transplantation for FHF in children, In: Pediatric transplantation supplement. 2003;7(4):79-81.

8. Bernuau J. Selection for emergency liver transplantation. J Hepatol. 1993;19:486-487.

9. Li W, Tiao M, Tsai C, et al. Factors predicting mortality in fulminant hepatic failure in children-17 years retrospective analysis. CJPG N. 2004;39:158-160.

10. Lee S, Mckieran P, Palrich K, et al. Etiology, outcome and prognostic indicators of childhood FHF in United Kingdom. JPGN. 2005;40(5): $575-581$.

11. Sue Hodgson. Hepatology: A textbook of liver disease. Zakim D and Boyer TH editor. Philadelphia, London, New York, St Louis, Sydney: Toronto; 2003. p. 445-470.

12. Chen H, Chan P, Kong M, et al. Outcome of fulminant hepatic failure in children in relation to $\mathrm{HBV}$ infection after universal vaccination program JPGN. 2004;39(1):s91-s92.

13. Aydogdu S, Ozgenc F, Yurtsever S, et al. Our experience with fulminant hepatic failure in Turkish children. Etiology and outcome. J Trop Pediatr. 2003;49(6):367-370.

14. Ekanem EE, Etuk IS, Uniga AJ. Features of childhood hepatic failure in Galbar: Nigeria. Niger Postgrad Med J. 2001;8(2):86-89.

15. Williams R, Gimson AE. Intensive liver care and management of acute hepatic failure. Dig Dis Sci. 1991;36:820-826.

16. Miyake Y, Sakaguchi K, Jwasaki Y, et al. New prognostic scoring model for liver transplantation in patients with non acetaminophen-related fulminant hepatic failure. Transplant. 2005;15:80-88.

17. Chan PC, Chen HL, Kong MS, et al. Factors affecting the mortality of pediatric fulminant hepatic failure in relation to hepatitis B virus infection. Gastroenterol Hepatol. 2005;20(8):1223. 
18. Rivera T, Moreno J, Skaff CH, et al. Delayed encephalopathy in fulminan hepatic failure in the pediatric population and role of liver transplantation. J Ped Gast \& Nut. 1997;24(2):128-134.

19. Sachin V, Bendre A, Ashish R, et al. Fulminant hepatic failure: etiology, viral markers and outcome. Indian Pediatrics. 1999;36: 1107-1112.

20. Pendey CK, Singh N, Kumar V, et al. Typhoid, hepatitis E or Typhoid and hepatitis E: The cause of fulminant hepatic failure: A diagnostic dilemma. Crit Care Med. 2002;30(2):376-378.

21. Kamath PS, Jalihal A, Cakraborty A. Differentiation of Typhoid fever from fulminant hepatic failure in patients presenting with jaundice and encephalopathy. Mayo Clinic Proc. 2000;75(5):462-466.

22. Molina RA, Krogstad P, Martin MG. Early evidence of bone marrow dysfunction in children with indeterminate fulminant hepatic failure who ultimately develop aplastic anemia. Am J Transplant. 2004;4(10):16561661.

23. Tung J, Hadzic N, Layton M, et al. Bone marrow Failure in children with acute liver failure. J Pediatr Gastroenterol Nutr. 2000; 31(5):557-61.

24. Uzma SH, Zehara H. Liver failure attributable to hepatitis A virus infection in a developing country. Pediatrics. 2000;105:436-438.

25. Tissieres P, Cheveret L Debray D, et al. Fulminant Wilson disease in children: appraisal of a critical diagnosis. Pediatr Crit Care Med. 2003;4(3):338-343.

26. Suhhaveva G, Tsaregorodtseva T, Petrakov A, et al. A Hepatic Leasion in patients with hepato-cerebral dystrophy. Ter Arkh. 2006;78(2):52-57.
27. Kalkan A, Bulut V, Avci S, et al. Trace element in viral hepatitis. J Trace Elem Med Biol. 2002;16(2):227-230.

28. Kumar A, Yachha K, Poddar U, et al. Dose co-infection with multiple viruses adversely influence the course and outcome of sporadic viral hepatitis in children. Gastroentrol Hepatol. 2006;21(10):1533-1537.

29. Ichai P, Afonso AM, Sebagh M, et al. Herpes Simplex Virus-associated acute liver failure: A difficult diagnosis with a poor prognosis. Liver Transpl. 2005;11(12):1550-5.

30. Miyake I, Wasaki Y, Terada R, et al. Clinical characteristic of fulminant type autoimmune hepatitis: An analysis of eleven cases. Aliment Pharmacol Ther. 2006;23(9):1347-53.

31. Kessler R, Cumming W, Eckert G, et al. Fulminant hepatitis as the initial presentation of acute autoimmune hepatitis. Clin Gastroenterol Hepatol. 2004;2(7):625-631.

32. Cuarterolo M, Lopez S, G deDavila M, et al. Autoimmune hepatitis in children: Initial presentation as fulminant hepatic failure. Acta Gastroentrol Latinoam. 2000;30(4):245-7.

33. Macquillan GC, Seyam MS, Nightingale P, et al. Blood lactate but not serum phosphate levels can predict patient outcome in fulminant hepatic failure. Liver Transpl. 2005;11(9):1073-1079.

34. Chan PC, Chen HL, Ni YH, et al. Outcome predictors of fulminant hepatic failure in children. J Formos Med. 2004;103(6):432-6.

35. Dabosk J, Newsome PN, Parkinson JA, et al. A biochemical prognostic model of outcome in paracetamol-induced acute liver injury. Transplantaion. 2005;80(12):1712-17. 